\title{
Natural fiber nonwoven reinforced cement composites as sustainable materials for building envelopes
}

\author{
Josep Claramunt \\ josep.claramunt@upc.edu \\ Departament d'Enginyeria Agroalimentària i Biotecnologia \\ Universitat Politècnica de Catalunya \\ Avinguda del Canal Olímpic, 15. E-08860 Castelldefels (Spain) \\ Lucía J Fernández-Carrasco \\ lucia.fernandez@upc.edu \\ Departament de Tecnologia de l'Arquitectura \\ Universitat Politècnica de Catalunya. \\ Pere Serra, 11-15. E-08190 Sant Cugat del Vallès (Spain)
}

Heura Ventura

heura.ventura@upc.edu

Departament d'Enginyeria Tèxtil i Paperera.

Universitat Politècnica de Catalunya.

C/Colom, 11, E-08222, Terrassa (Spain)

\author{
Mònica Ardanuy* \\ monica.ardanuy@upc.edu
}

Departament d'Enginyeria Tèxtil i Paperera.

Universitat Politècnica de Catalunya-Barcelona Tech.

C/Colom, 11, E-08222, Terrassa (Spain) 


\begin{abstract}
This experimental research analyzes the mechanical performance and durability of façade pieces based on Portland cement matrix and flax nonwovens as reinforcement. Two types of pozzolanic additions (silica fume and metakaolin) combined with nonwovens subjected to different treatments to decrease their water absorption are analyzed as potential materials for fiber-cement sheets for building envelopes with high strength and durability. For this purpose, on the one hand, the mechanical performance and chemical composition of various ternary compositions were studied. On the other hand, various treatments were performed on the nonwovens and the nonwoven-matrix adherence was also analyzed. Finally, composites were prepared from some selected treated nonwovens and matrix mixtures, and their mechanical properties and durability were evaluated under four-point bending tests after 28 days of curing in a humidity chamber and after accelerated aging. The composites developed with the treated nonwovens presented very high performance combined with enough durability to be potential candidates for the development of sustainable materials for building envelopes.
\end{abstract}

\title{
Highlights
}

- Mechanical performance and durability of OPC/flax nonwovens composites for façade pieces is explored

- The effect of two pozzolanic additions combined with nonwoven treatment is evaluated

- Significant improvements in the durability using treated nonwovens 


\section{Introduction}

It is widely known that the rising carbon dioxide level in the atmosphere is causing an increase of the global temperature of the earth that demands an urgent global response. In this sense, the atmospheric concentration of $\mathrm{CO}_{2}$ has increased from a pre-industrial concentration of about $280 \mathrm{ppm}$ to around $390 \mathrm{ppm}$ at present. Although the Stern review advises that the $\mathrm{CO}_{2} \mathrm{e}$ should be stabilized between 450 and $550 \mathrm{ppm}$ to avoid the worst impacts of climate change, global emissions have grown at a rate of $3.7 \%$ during recent years [1].

Approximately $50 \%$ of these emissions are produced by the building sector, during both the construction and the operational phase of buildings. The building sector is responsible for about $40 \%$ of the European Union total final energy consumption and $36 \%$ of its total $\mathrm{CO}_{2}$ emissions [2]. Innovations to improve the energy efficiency of buildings are thus of practical importance.

To reduce $\mathrm{CO}_{2}$ emissions, the involvement of the construction sector is necessary in all possible areas, that is to say, both during the operational lifetime, which accounts for over $80 \%$ of the gas emissions, and during the manufacture and transport of materials, construction, maintenance, and demolition, which generally account for 10 to $20 \%$ of the energy consumption [3].

With respect to the manufacture of the materials, the use of more environmentally friendly materials obtained from renewable sources with sustainable processes could be an interesting solution for the reduction of $\mathrm{CO}_{2}$ emissions [4].

Concerning the lifetime use of the building, the design of new construction solutions combined with adequate energy consumption management can lead to a significant reduction of the energy expenditure for lighting and air conditioning. More concretely, the construction solution known as the "ventilated façade" system has experienced a significant increase in use in Europe, especially the Mediterranean countries, due to both its good performance and its ease of construction and in both new buildings, especially offices and residences, and the rehabilitation of buildings [5].

Ventilated façades are multi-layered building envelopes consisting of an outer layer mechanically connected to an inner layer and a ventilated air gap that usually contains thermal insulation in contact with the inner layer. Each of the layers has a specific function, as can be seen in Figure 1. The provision of an external discontinuous protective envelope, separated from the insulation layer, allows air ventilation and 
prevents heating by direct sunlight or by transmission through the coating layer surface, thus improving the internal comfort of the building, especially in hot climates with intense solar radiation. This outer envelope, apart from its aesthetic function, should protect against heat radiation, rain, and wind and should form an air chamber. So, the material used for this outer layer has to fulfill certain requirements such as strength, flexibility, ductility, lightness, permeability, thermal and acoustical insulation, and durability, among others.

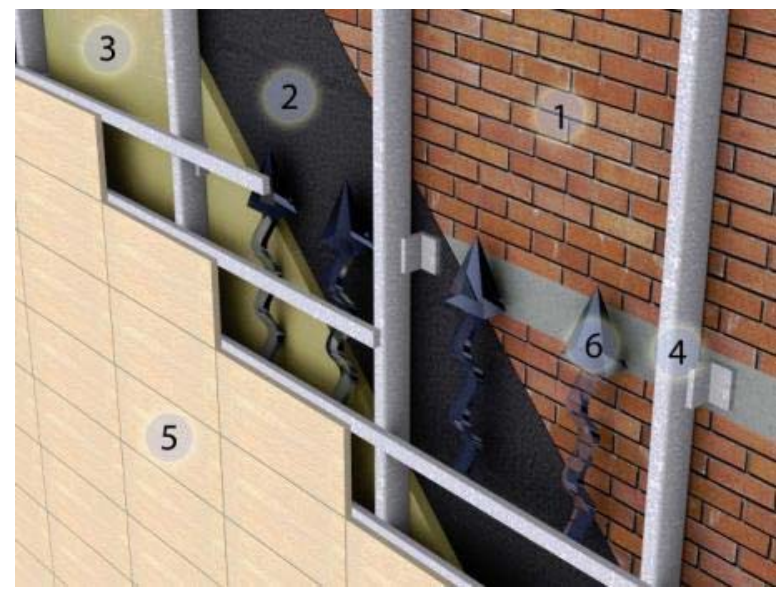

Figure 1. Image of layers of a ventilated façade system: 1. Inner wall; 2. Breathable and waterproof sheet; 3. Continuous insulating layer; 4. Load-bearing structure; 5. Joined building wall; 6. Ventilated air gap.

Currently the materials most commonly used for these envelopes are ceramics, natural stones, wood-resin and aluminum-resin composites, and, increasingly, fiber cements. Each of these materials has advantages with regard to some requirements but not all of them. For example, ceramics and natural stones have excessive weight and high stiffness, which limits their size and necessitates a complex supporting structure. Furthermore, partial breaking, which can lead to objects falling on public roads, can be dangerous. Wood and aluminum composites are more flexible and lightweight but are less durable, have lower hardness, and are much more expensive and less sustainable compared to conventional building materials. For these reasons it is of practical importance to develop new materials for envelopes with the maximum aforementioned characteristics: primarily strength, ductility, flexibility, and durability, using environmentally friendly and low-cost raw materials and processes.

One possible solution is the use of vegetable fiber cement reinforced composites. The use of cellulosic or vegetable fibers has emerged during the last decades as an interesting option to substitute for asbestos, allowing the development of materials with 
good performance at relatively low cost [6-9]. Cellulosic fibers provide adequate stiffness, strength, and bonding capacity to cement-based matrices, enhancing their flexural strength, toughness, and crack resistance. Moreover, vegetable fibers are nonhazardous, renewable, and biodegradable, allowing the development of more sustainable construction materials.

Many studies describing the use of cellulose-based fibers as a reinforcement for cement-based composites have been published [10-17]. Nonetheless, in most of these papers the fibers are used in pulp or staple forms, limiting the improvement of the flexural strength and ductility of the composites, owing to the short length of the fibers, and the maximum quantity that it is possible to mix with the cement matrix (around 4-6 wt.\%). In order to overcome these problems, Toledo Filho et al. [18] used unidirectional sisal strands to reinforce cement-based composites, which significantly improved the tensile strength and toughness [19-21]. Although interesting results are obtained with these strands, it is difficult to produce these composites industrially using an automated laminating process. Therefore, recently Claramunt et al. [22,23] developed composites reinforced with nonwovens made of flax fibers. These structures allow handleability and easier applicability for automated processes [24].

Despite all the aforementioned advantages of these composites, one of the main drawbacks is the loss of mechanical properties after accelerated aging. It is well known that this lack of durability is mainly caused, on the one hand, by the calcium hydroxide (portlandite) of the matrix, which degrades the fibers, and, on the other, by changes in environmental moisture, which induce dimensional changes in the vegetable fibers and hence loss of physical contact with the matrix [25-27]. To overcome the problem of the calcium hydroxide component, several strategies have been used, such as pozzolanic additions to precipitate the portlandite as calcium silicate hydrate [28-35] or carbonation treatments with $\mathrm{CO}_{2}$ to precipitate the portlandite as calcium carbonate [36]. Concerning the pozzolanic additions, Cyr et al. [37] stated that the reactivity of the pozzolan depends on the alkalinity of the matrix and on the fineness of the particles of the mixtures. This indicates that it is important to analyze the reactivity of every system.

To minimize the dimensional changes of the fibers, chemical or physical modifications can be carried out. One successful treatment is to subject the fibers to wetting and rewetting cycles in water, causing shrinkage of the fibers and a reduction in water-retention values due to the formation of hydrogen bonds in the cellulose. This irreversible effect [38-40], known as "hornification" and quantified as the percentage 
reduction in the water-retention value (WRV), occurs in the cell wall matrix of the fibers, resulting in intensely bonded structures [41]. This simple and ecofriendly treatment, which uses water as the reagent, has been used successfully to obtain more durable cement composites reinforced with cellulose pulps [42,43], or sisal strands [44].

The aim of this work it to analyze the mechanical performance and durability of façade pieces based on Portland cement matrix and cellulosic fiber nonwovens as reinforcement. Two types of pozzolanic additions (silica fume and metakaolin) combined with nonwovens subjected to different treatments to improve their dimensional stability are analyzed as potential materials for fiber-cement sheets for building envelopes with high strength and durability. The mechanical properties and durability are evaluated under four-point bending tests after 28 days of curing in a humidity chamber and after subjecting the sheets to accelerated aging.

\section{Materials and experimental procedures}

\subsection{Materials}

UNE-EN 197-1:2011 Type I cement, supplied by Lafarge (Spain), was used as the matrix. As the pozzolanic additions, silica fume (SF, sourced from Sika S.A.U.) and metakaolin (MK, sourced from Arcillas Refractarias S.A.) were used. Sika Viscocrete-3425 fluidizer (obtained from Sika S.A.U.) was used to aid the workability of the mixtures.

Short flax fibers (with an average length of $6 \mathrm{~cm}$ ) provided by Fibres Reserche Development of the Technopole de l'Aube en Champagne (France) were used to prepare the nonwoven reinforcement.

\subsection{Dosage and mechanical characterization of the matrix}

Seven mixtures were prepared with different proportions of silica fume and metakaolin to replace between 30 and $60 \%$ of the Portland cement. These intervals were selected based on previous works since allow to maintain the strength of the matrix with a reduction of the calcium hydroxide $[12,18,45-47]$. The initial water/binder ratio was initially fixed at 0.3 and was modified to maintain the self-compacting property in all the samples. The content of fluidizer was also modified to maintain the consistency in all the 
samples. The percentages of the different blended materials and the dosages are given in Table 1.

Table 1. Mixture proportions of the samples prepared.

\begin{tabular}{|c|c|c|c|c|c|}
\hline \multirow{2}{*}{ Sample } & \multicolumn{3}{|c|}{ Proportion (wt.\%) } & \multirow{2}{*}{ water/binder } & \multirow{2}{*}{ Fluidizer/binder } \\
\hline & Cement & SF & MK & & \\
\hline $\mathrm{C} 0$ & 1 & 0 & 0 & 0.35 & 0.004 \\
\hline C10FS20MK & 0.7 & 0.1 & 0.2 & 0.32 & 0.004 \\
\hline C10FS30MK & 0.6 & 0.1 & 0.3 & 0.32 & 0.004 \\
\hline C10FS40MK & 0.5 & 0.1 & 0.4 & 0.33 & 0.004 \\
\hline C20FS20MK & 0.6 & 0.2 & 0.2 & 0.30 & 0.004 \\
\hline C20FS30MK & 0.5 & 0.2 & 0.3 & 0.30 & 0.004 \\
\hline C20FS40MK & 0.4 & 0.2 & 0.4 & 0.30 & 0.004 \\
\hline
\end{tabular}

Eighteen specimens of $20 \times 40 \times 160 \mathrm{~mm}^{3}$ were prepared for each sample $($. Flexural and compression tests were performed on an Incotecnic press after 7, 28, and 56 days after curing at $20{ }^{\circ} \mathrm{C}$ and $>95 \%$ relative humidity. A load cell of $3 \mathrm{kN}$ and a crosshead speed of $2 \mathrm{~mm} / \mathrm{min}$ were used for the flexural tests. The compression tests were performed on specimens of $20 \times 20 \times 40 \mathrm{~mm}^{3}$ with a load cell of $20 \mathrm{kN}$ and a cross-head speed of $1 \mathrm{~mm} / \mathrm{min}$.

Fourier Transformed Infrared Spectroscopy (FTIR) analysis was conducted to determine the presence of $\mathrm{Ca}(\mathrm{OH})_{2}$ remaining in the hydrated samples. A Nicolet 6700 Thermo Scientific spectrometer with a DGTS CsI detector was used. To characterize the pastes cured under different conditions, the reactions were frozen following a methodology described previously [48]. 


\subsection{Preparation, treatment, and characterization of nonwovens}

Nonwoven fabric samples were prepared on a DILO OUG-II-6 double needle-punching machine equipped with universal card clothing, cross-lapper, batt feeder, and needlepunching loom. The flax fibers were first opened and carded to form a thin web, which was laid by the cross-laying method to form batts. These batts were consolidated on the needle-punching machine to form the nonwoven mats.

Different wet-dry treatments were carried out on the nonwovens in order to increase moisture resistance $[42,49]$ (Table 2). All the treatments were performed five times. The wet treatments were performed in water (immersion for $2 \mathrm{~h}$ ) or steam at 120 ${ }^{\circ} \mathrm{C}$ in an autoclave (for $90 \mathrm{~min}$ ) and the subsequent drying steps were done by heating in an air ventilation oven (for 4 hours) or by heating in the oven followed by ironing at $190^{\circ} \mathrm{C}$ for $2 \mathrm{~min}$.

Table 2. Conditions of the wet-dry treatments carried out on the nonwovens.

\begin{tabular}{|l|ll|}
\hline Sample & Wet step & Dry step \\
\hline A-O160+I & Autoclave $120{ }^{\circ} \mathrm{C}$ & Oven $160^{\circ} \mathrm{C}+$ ironing \\
\hline W-O160+I & Water $20{ }^{\circ} \mathrm{C}$ & Oven $160^{\circ} \mathrm{C}+$ ironing \\
\hline A-O160 & Autoclave $120^{\circ} \mathrm{C}$ & Oven $160^{\circ} \mathrm{C}$ \\
\hline W-O160 & Water $20{ }^{\circ} \mathrm{C}$ & Oven $160^{\circ} \mathrm{C}$ \\
\hline A-O60 & Autoclave $120^{\circ} \mathrm{C}$ & Oven $60^{\circ} \mathrm{C}$ \\
\hline W-O60 & Water $20{ }^{\circ} \mathrm{C}$ & Oven $60^{\circ} \mathrm{C}$ \\
\hline
\end{tabular}

Moisture regain values were determined following the DIN 54351 standard. Tensile tests (based on the UNE-EN ISO 13934-1 standard) were performed to determine the changes in the breaking force of the nonwovens. The tests were done in an MTS machine with a load cell of $5 \mathrm{kN}$ using a displacement rate of $100 \mathrm{~mm} / \mathrm{min}$. The nonwovens were tested in both the machine direction (MD) and the cross-direction (CD).

All the nonwoven fabrics were conditioned at a standard temperature and relative humidity of $20 \pm 2{ }^{\circ} \mathrm{C}$ and $65 \pm 2 \%$, respectively, prior to testing.

\subsection{Fiber-matrix adhesion test}

For all the treated nonwovens, an adhesion test consisting of embedding a nonwoven specimen between two blocks of Portland cement (with a fixed water/cement ratio of 0.3 ) 
and subsequently subjecting the sandwich to a tensile test (Figure 2) was carried out. The tensile tests were performed on a Dynamic Mechanical Analyzer (DMA) TA-800 with a cross-head speed of $6 \mathrm{~N} / \mathrm{min}$. This configuration allows a tangential strength to be generated in both faces of the nonwoven.
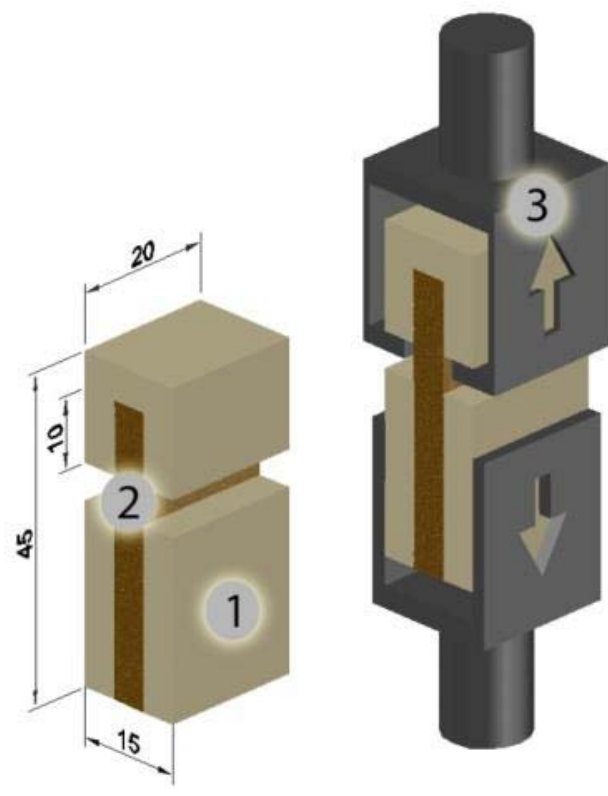

Figure 2. Left: dimensions of the specimen for adhesion tests in millimeters: (1) the matrix; (2) the nonwoven. Right: specimen fixed between the clamps (3).

Twelve specimens were prepared for each treatment and cured for 28 days at ambient temperature $\left(20^{\circ} \mathrm{C}\right)$ in a humidity chamber (approximately $95 \%$ relative humidity). Half of the specimens were used to perform the adhesion tests after curing and the other half were used to analyze the adhesion after accelerated aging under wet-dry cycles following the UNE-EN 12467 standard. The wet-dry cycle used was $18 \mathrm{~h}$ of soaking in water at room temperature followed by $6 \mathrm{~h}$ of drying in an oven provided with open air circulation at $60^{\circ} \mathrm{C}$. A total of 20 wet-dry cycles were performed.

\subsection{Composite preparation and characterization}

For the composite preparation, the methodology used was application of the reinforcement by taking special care in the wetting of the nonwoven with the matrix. This 
was done in a mold with internal dimensions of $300 \times 300 \times 10 \mathrm{~mm}^{3}$ that was specially designed to apply homogeneous pressure (3.5 MPa)[12,45] (Figure 3). Laminates of five nonwoven cross-oriented layers were produced. The excess water was eliminated and the samples were reduced to a thickness of $8-12 \mathrm{~mm}$. The plates were cured for 28 days at ambient temperature $\left(20^{\circ} \mathrm{C}\right)$ in a humidity chamber (approximately $95 \%$ relative humidity). Two plates were produced for each nonwoven selected and two more for the control test (same matrix, untreated nonwoven). From each plate, six specimens with dimensions close to $10 \times 40 \times 300 \mathrm{~mm}^{3}$ were machined. One plate was used to perform the mechanical characterization after curing and the other to analyze the degradation of the composites after accelerated aging under 50 wet-dry cycles following the UNE-EN 12467 standard.

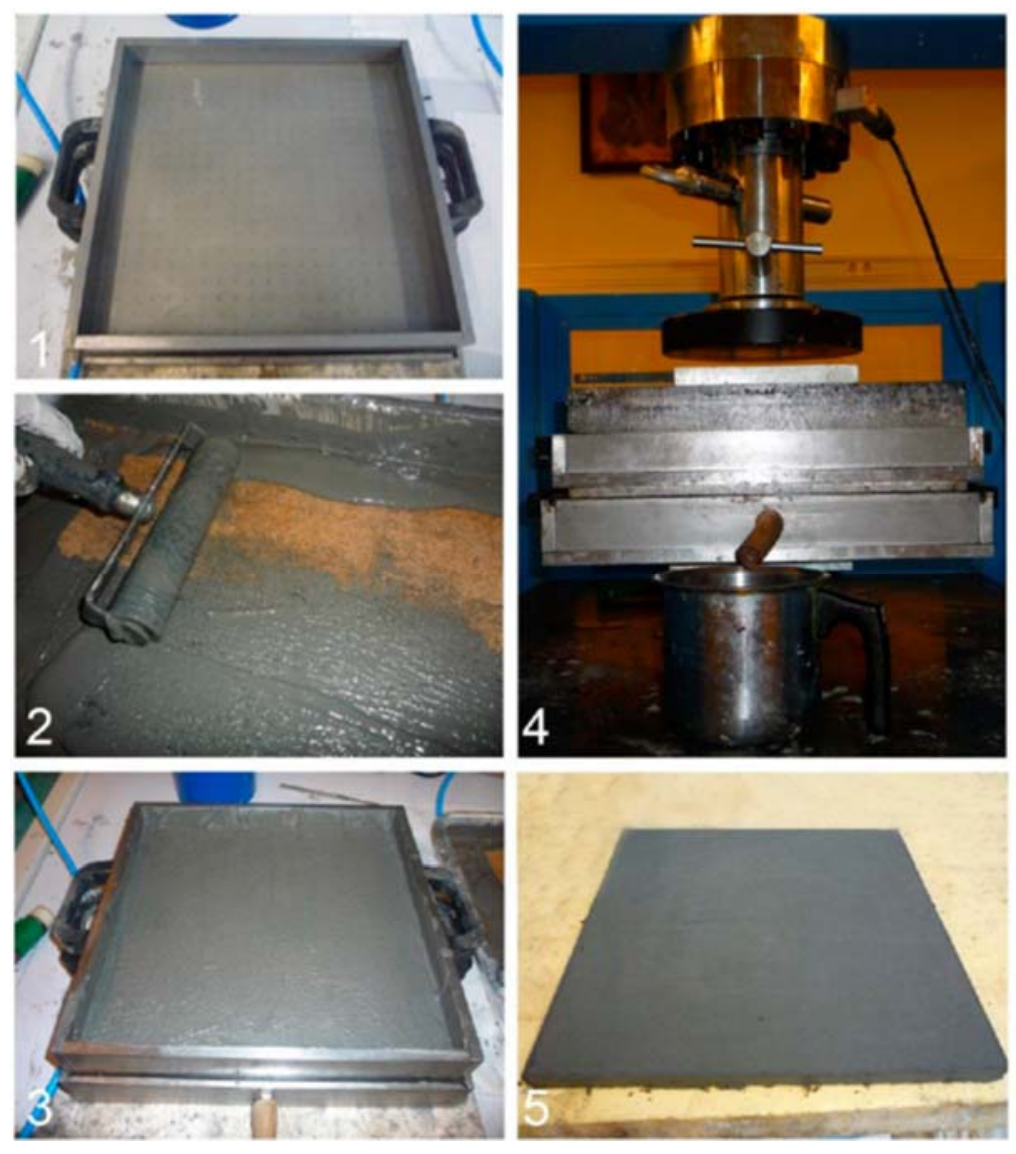

Figure 3. Images of the steps followed for the preparation of the composite's plates: (1) mold; (2) impregnation of the nonwovens with the cement matrix; (3) laminate with five nonwoven layers; (4) application of pressure; (5) finished plate

Four-point bending tests were carried out following the International Union of Laboratories and Experts in Construction Materials, Systems and Structures (RILEM) 
TFR1 standard test using an Incotecnic press equipped with a maximum load cell of $3 \mathrm{kN}$ at a cross-head speed of $2 \mathrm{~mm} / \mathrm{min}$. The major span (L) was $270 \mathrm{~mm}$, and the displacement measurements were carried out using two linear variable differential transformer (LVDT) with a resolution of $0.01 \mathrm{~mm}$ and an error of $0.15 \%$. The modulus of rupture (MOR), modulus of elasticity (MOE), and the energy absorbed or toughness values were obtained from force-displacement curves.

\section{Results and discussion}

3.1 Effect of the pozzolanic addition on the mechanical properties and chemical composition of the matrix.

Figures 4 and 5 show the values of compressive and flexural strength for the matrix with different dosages tested after 7, 28, and 56 days of curing. In general terms, as can be seen, and compared with the reference, all the additions lead to a decrease of the flexural and compressive strength. Only for the sample containing less pozzolanic addition (C10FS20MK) slightly higher values were obtained for compressive strength and flexural strength with respect to the reference at curing times of 7 days and 56 days respectively.

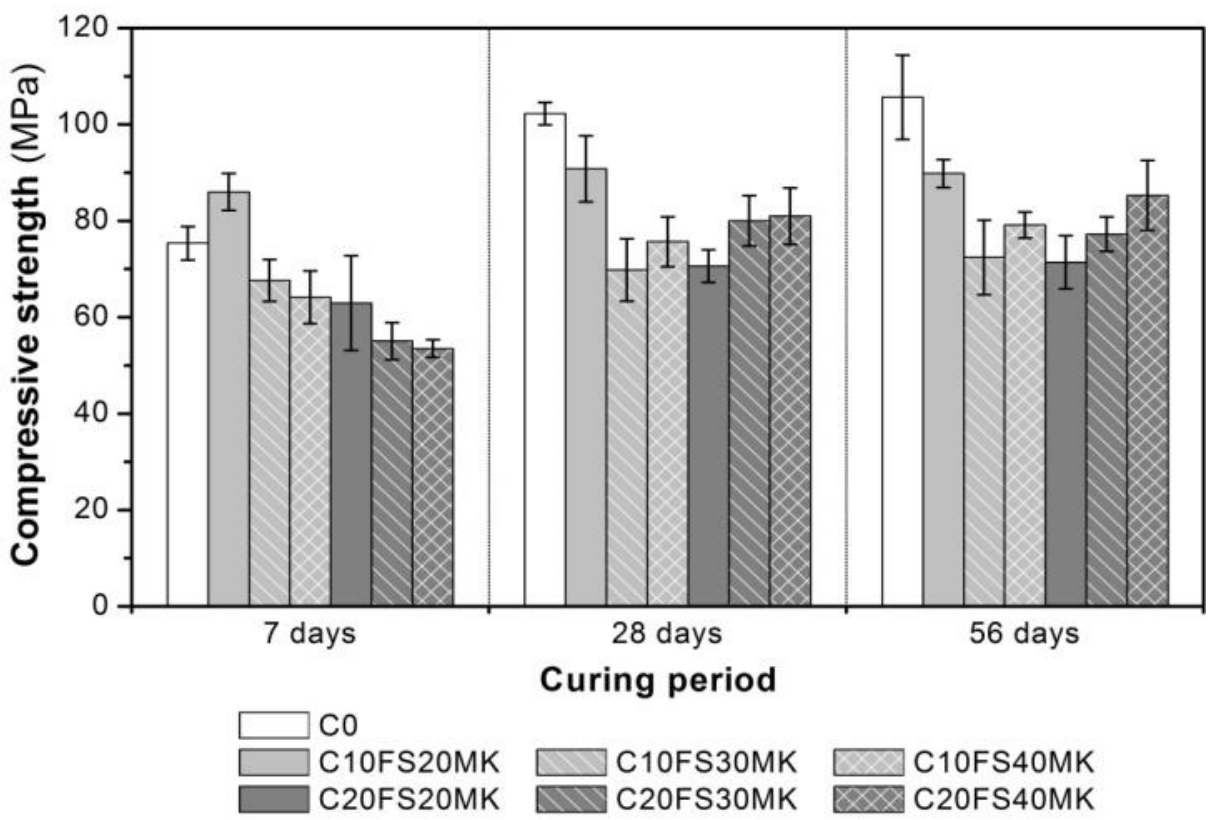

Figure 4. Results of compressive strength tests performed on the cement pastes without addition (C0); with 10 wt.\% addition of SF and 20, 30 or 40 wt.\% of MK (C10Fs20MK, C10FS30MK and C10FS40MK respectively) and with $20 \mathrm{wt} . \%$ addition of SF and 20, 30 or 40 wt.\% of MK (C20Fs20MK, C20FS30MK and $\mathrm{C} 20 \mathrm{FS} 40 \mathrm{MK}$ ) respectively, after 7,28 , and 56 days of curing. 


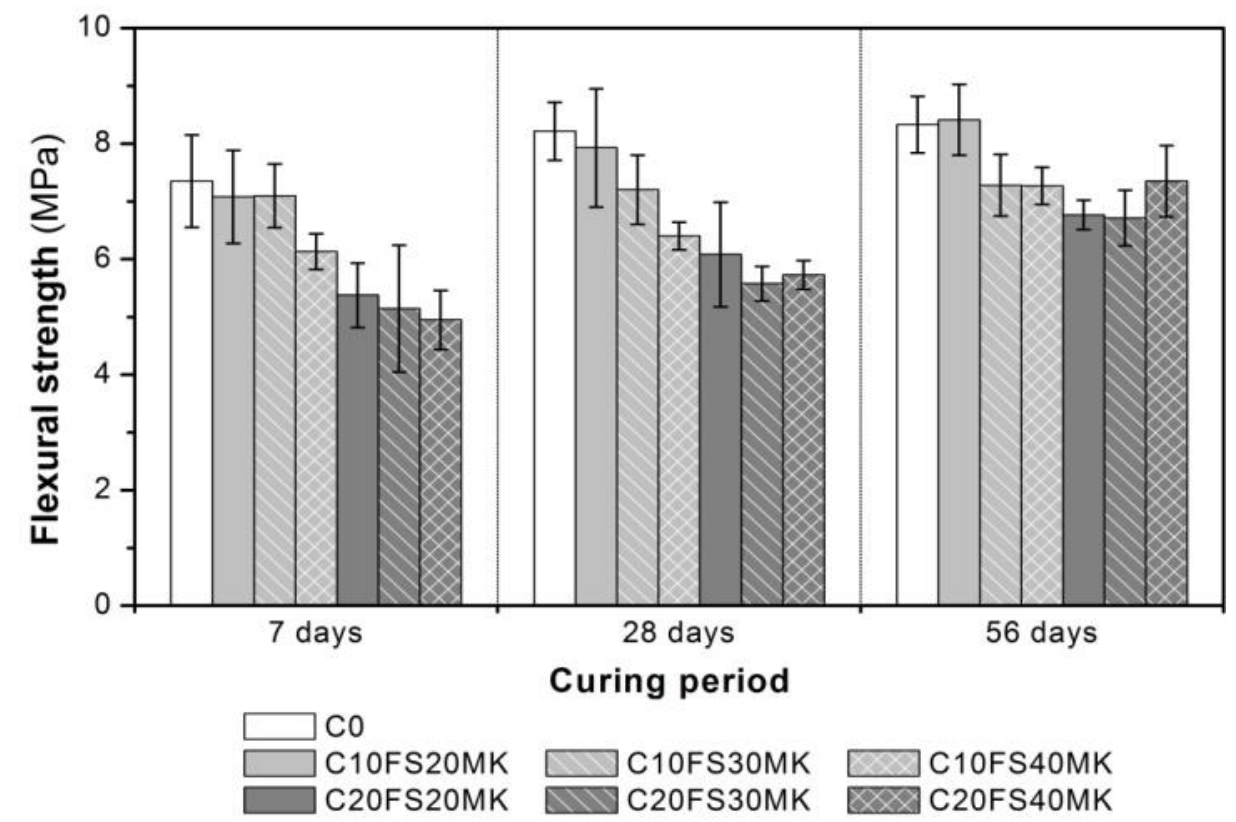

Figure 5. Results of flexural strength tests performed on the cement pastes without addition (C0); with 10 wt.\% addition of SF and 20, 30 or 40 wt.\% of MK (C10Fs20MK, C10FS30MK and C10FS40MK respectively) and with $20 \mathrm{wt} . \%$ addition of SF and 20, 30 or 40 wt.\% of MK (C20Fs20MK, C20FS30MK and C20FS40MK) respectively, after 7, 28, and 56 days of curing.

Figures 6 and 7 show the evolution of the flexural strength and compressive strength with respect to the cement content for the samples cured for 56 days, when more time was available for the pozzolanic reactions. As can be seen, the compressive strength decreases with the content of pozzolan until a minimum value is reached at a pozzolan content of $40 \%$. After this value there is an increase of the compression strength up to a pozzolan content of $60 \%$. With respect to flexural strength, the minimum value is obtained for pozzolan contents between 40 and 50\%. Moreover, as shown, the compressive strength values are not dependent on the percentage of pozzolan in the mixture, regardless of whether 10 or $20 \%$ SF is used; however, the flexural strength values are in general superior with the $10 \%$ SF mixtures. These results can be explained by the higher dependence of the particle size of SF and alkalinity than the reactive silica presence as was found by Cry et al. [37]. 


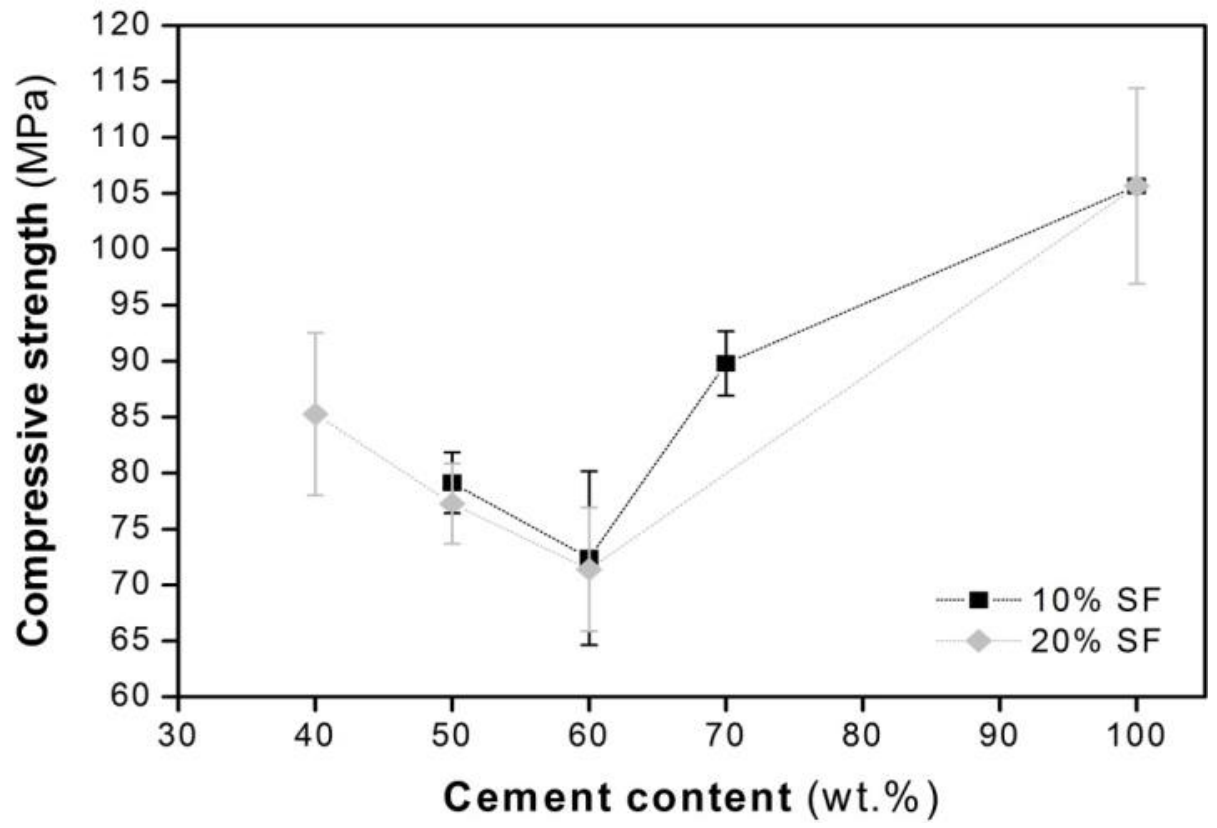

Figure 6. Relationship between the values of compressive strength and cement content in the mixtures with $10 \mathrm{wt} . \%$ and $20 \mathrm{wt} . \%$ of SF addition and 20, 30 and $40 \mathrm{wt} . \%$ of MK cured for 56 days.

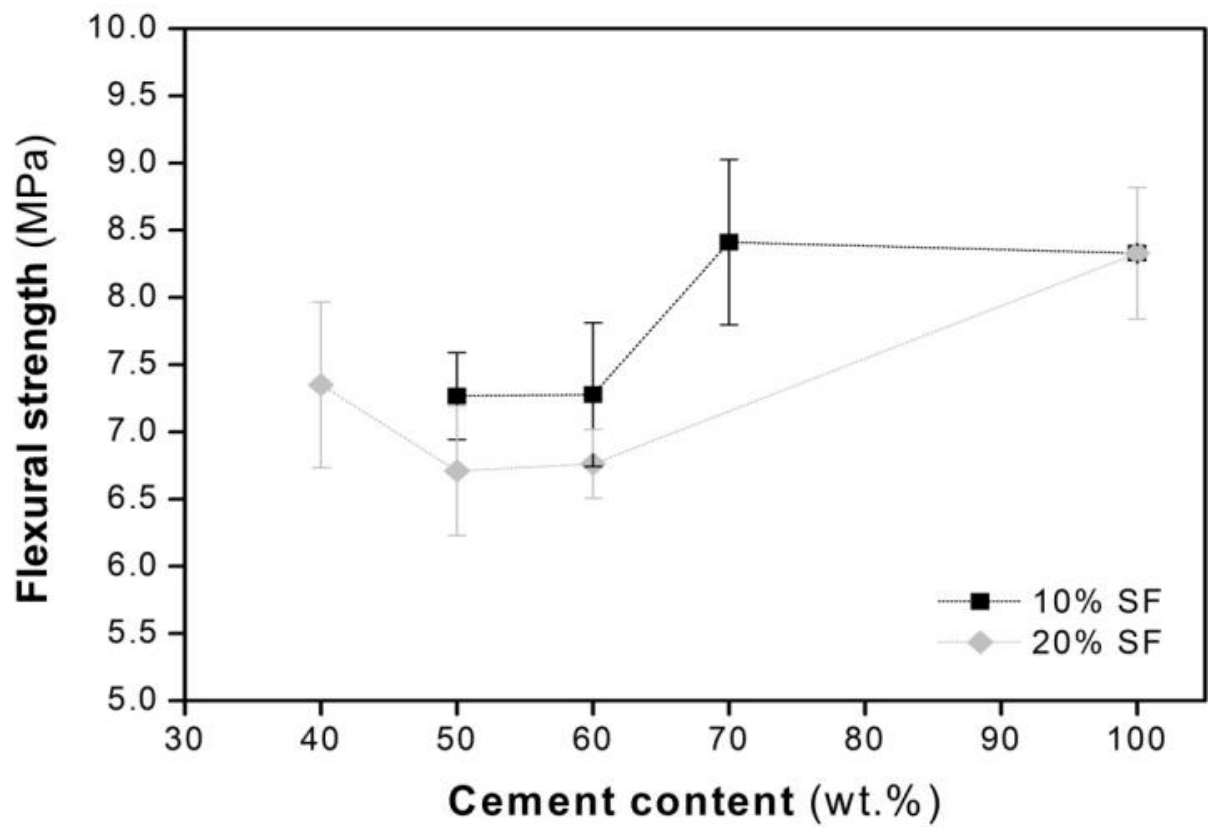

Figure 7. Relationship between the values of flexural strength and cement content in the mixtures with 10 wt. $\%$ and $20 \mathrm{wt} . \%$ of SF addition and 20,30 and $40 \mathrm{wt} . \%$ of MK cured for 56 days.

On the other hand, as shown in Figure 8, for the samples with pozzolan contents higher than $40 \%$, the highest increase of compressive strength is observed for curing times of 
between 7 and 28 days, while the increase of flexural strength mainly occurs between curing times of 28 and 56 days.

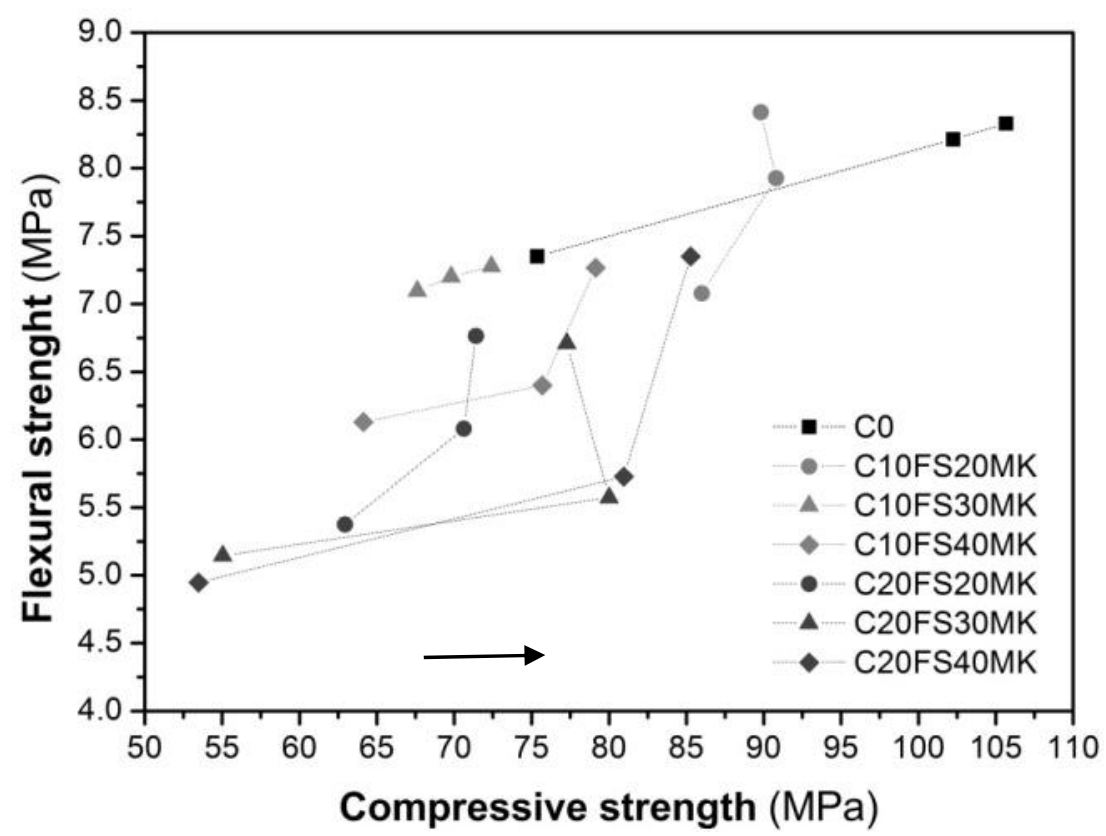

Figure 8. Relationship between the values of flexural strength and compressive strength for the cement pastes without addition (C0); with 10 wt.\% addition of SF and 20, 30 or 40 wt.\% of MK (C10Fs20MK, C10FS30MK and C10FS40MK respectively) and with $20 \mathrm{wt} . \%$ addition of SF and 20, 30 or $40 \mathrm{wt} . \%$ of MK (C20Fs20MK, C20FS30MK and C20FS40MK) respectively, cured for 7, 28, and 56 days.

Samples C10FS20MK and C20FS40MK were selected to determine the presence of remaining $\mathrm{Ca}(\mathrm{OH})_{2}$ with FTIR analysis. The first sample was chosen because it had the highest mechanical performance and the second because it had the lowest cement content combined with well-balanced mechanical performance. $\mathrm{C} 0$ was also analyzed for comparison. FTIR spectra of these samples are shown in Figure 9.

As can be seen, all the spectra show a broad absorption band in the range of 3800-3000 $\mathrm{cm}^{-1}$, which corresponds to $\mathrm{OH}$ stretching vibrations of water molecules of calcium silicate hydrate $(\mathrm{C}-\mathrm{S}-\mathrm{H})$ gel with maxima close to $3450 \mathrm{~cm}^{-1}$. The absorption peak at around $3645 \mathrm{~cm}^{-1}$ corresponds to portlandite $\left(\mathrm{Ca}(\mathrm{OH})_{2}\right)$. Other important bands are the 
ones due to the tetrahedral $\mathrm{SiO}_{4}$ groups of C-S-H gel, which appeared at $980 \mathrm{~cm}^{-1}$ in the spectra, and the $1118 \mathrm{~cm}^{-1}$ band, ascribed to sulfate groups of ettringite ( $\left.\mathrm{v}_{3} \mathrm{SO}_{4}\right)$.

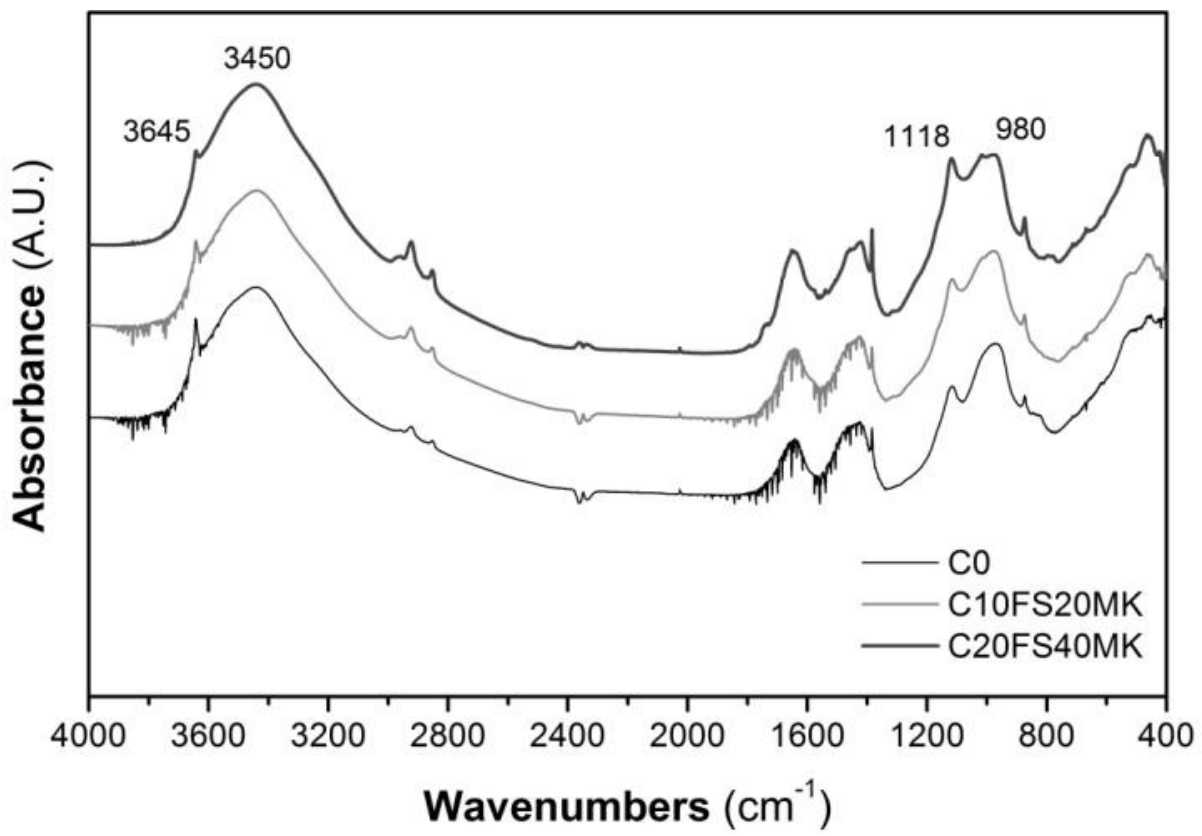

Figure 9. FTIR spectra of the samples the cement pastes without addition (C0); with $10 \mathrm{wt} \%$ addition of SF and 20 wt.\% of MK (C10FS20MK) and with 20 wt.\% addition of SF and 40 wt.\% of MK (C20FS40MK) cured for 56 days.

As expected, in the spectra of the samples with pozzolanic addition, less portlandite was detected, which indicates that the silica fume and metakaolin reacted with the previously generated portlandite in a pozzolanic reaction. Although a complete disappearance of portlandite was not found, in the sample with a higher content of pozzolan (C20FS40MK), a lower content of portlandite was found.

Taking into account all of these results, the C20FS40MK matrix was selected as the most appropriate one for the preparation of the composites for the durability test.

\subsection{Effect of wet-dry treatment on the flax-fiber nonwovens' properties}

Figure 10 shows the moisture regain values and the mechanical properties of the treated and untreated nonwovens. As expected, lower values of moisture regain were observed in the treated nonwovens compared to the untreated one; that is, the treated nonwovens were more stable with respect to environmental humidity changes [49]. Nevertheless, 
this decrease in moisture regain values was slightly higher for the nonwovens ironed in the dry step (A-Oi and W-OI samples).

On the other hand, with regard to the values of breaking force, two groups of behaviors can be observed. As shown, the samples subjected to drying in the oven at high temperature $\left(160^{\circ} \mathrm{C}\right)$ followed by ironing and the sample treated in an autoclave followed by drying at high temperature had higher values of maximum force at breaking compared with the untreated nonwoven. The other treatments led to values similar to those of the untreated fabric. This change in the mechanical properties is related to the shrinkage of the fabrics due to the effect of the wet-dry water cycles, which is more noticeable when the nonwovens are treated in more aggressive conditions.

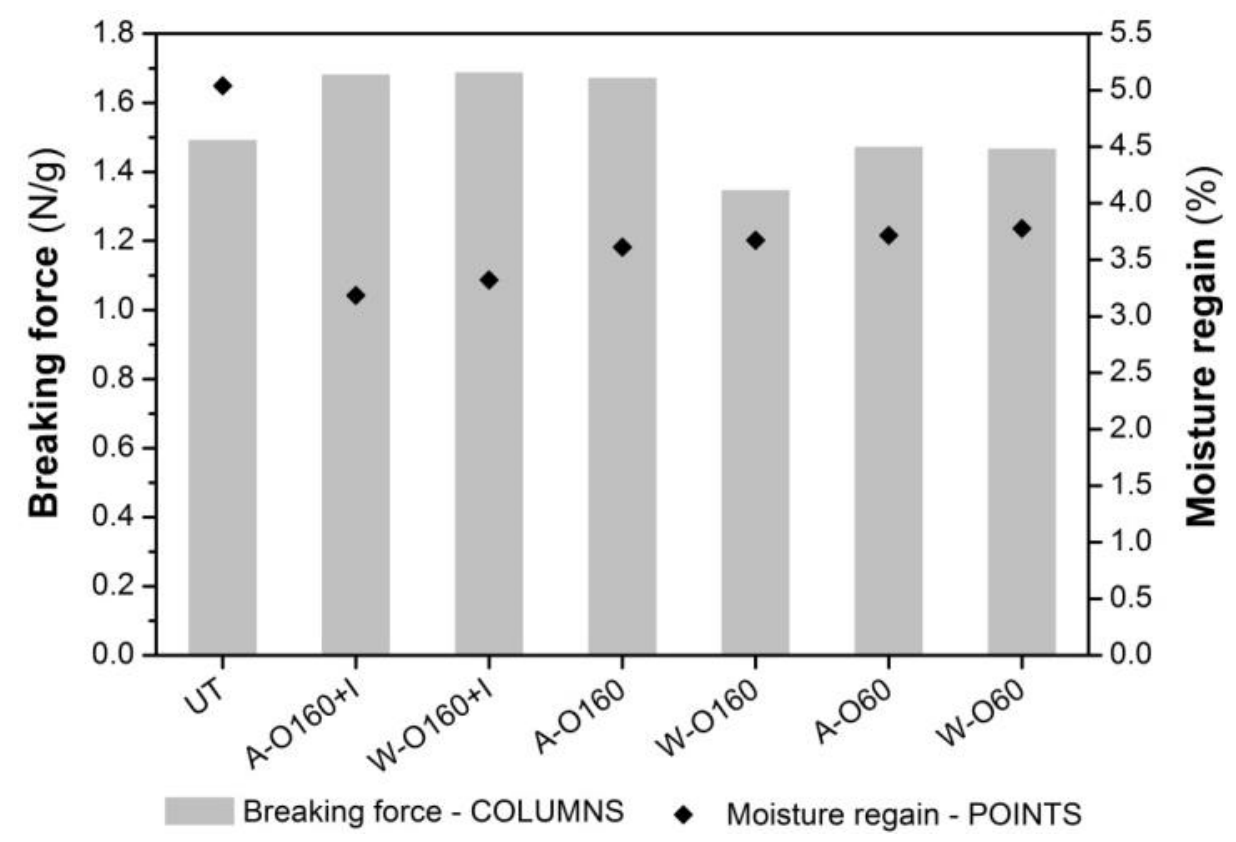

Figure 10. Values of breaking force and moisture regain of the untreated nonwoven (UT) compared with the treated ones under different conditions

Based on these results, the best candidates for preparing the composites must be the ones with the higher values of breaking force combined with the lower values of moisture regain. The samples A-O160+I and W-O160+I presented the higher values of breaking force (1.68 and $1.69 \mathrm{~N} / \mathrm{g}$ respectively) combined with the lower values of moisture regain (3.18 and $3.33 \%$ respectively). 


\subsection{Effect of the treatment of the nonwovens on the fiber-matrix adherence}

Figure 11 shows the average of the nonwoven-matrix bonding force for the untreated nonwovens and those treated in different conditions. It can be observed that all the treatments analyzed in this work improved the bond between the fibers and the cement. Those improvements could be related to the increase in the breaking force of the nonwovens, as shown in Figure 10. The best treatment in terms of improved adhesion bond for the unaged samples was found to be the treatment with the autoclave followed by drying at high temperature and ironing. This treatment was also the one with lower standard deviation for the values of bonding. The other analyzed treatments led to similar improvements in bonding.

With respect to the aged samples, it was only possible to perform the tests on the samples A-O160+I, W-O160+I, and A-O160, since for the untreated sample and the sample treated with water followed by drying at high temperature, the nonwoven became detached from the matrix without applying any force. As shown, there was a significant decrease of the nonwoven-matrix bonding after aging of the samples. The best performance was found for the $\mathrm{W}-\mathrm{O} 160+\mathrm{I}$ sample, with an average decrease of bonding force of $49 \%$, followed by the A-O160+I and A-160 treatments, with decreases of 78 and $87 \%$ respectively. Based on these results and the ones presented on the previous section, the samples $\mathrm{W}-\mathrm{O} 160+\mathrm{I}$ and $\mathrm{A}-160+\mathrm{I}$ were selected to prepare the composites. 


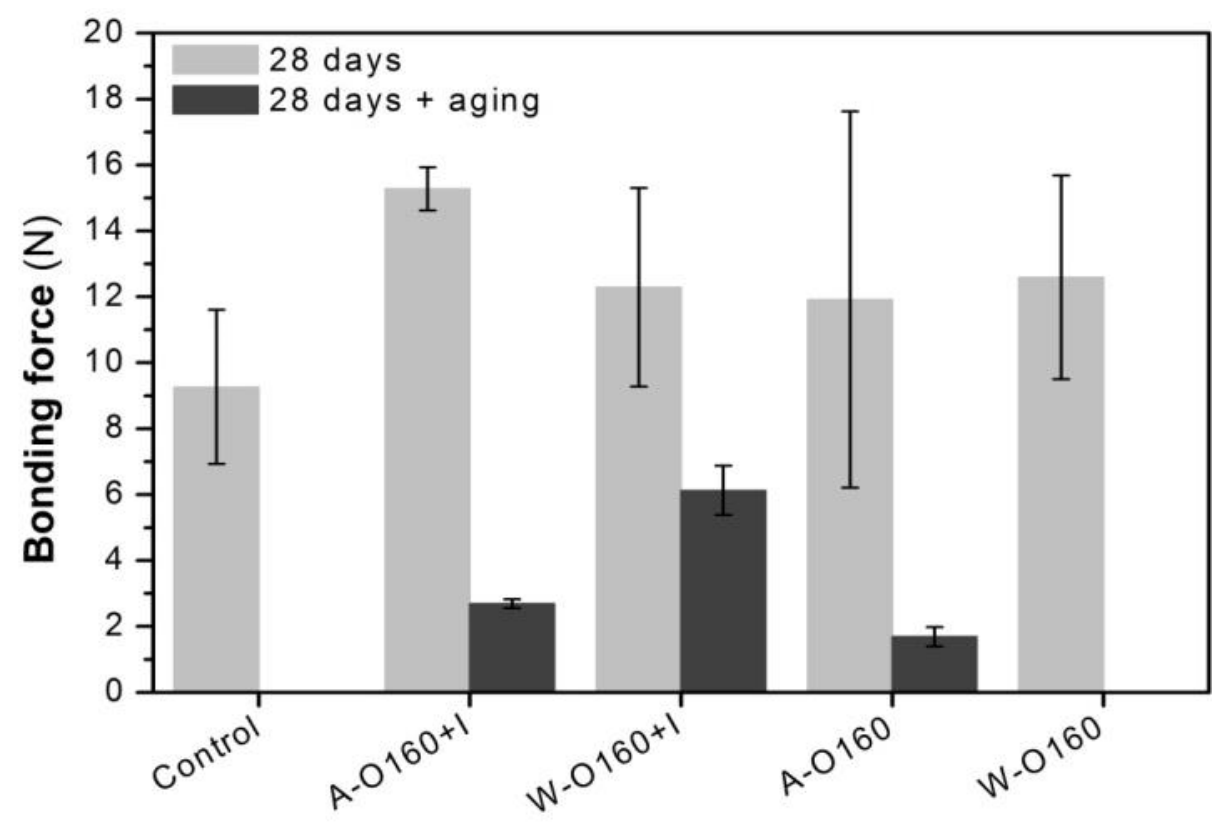

Figure 11. Average values of nonwoven-matrix adhesion for the composite prepared with the uncreated nonwoven (control) and the ones prepared with the nonwovens treated under different conditions cured for 28 days and the ones cured and subjected to accelerated aging.

\subsection{Effect of nonwoven treatment on the composite properties}

After selecting the optimum nonwoven treatments, composites with the untreated and treated nonwovens were characterized by bending tests to evaluate the mechanical performance after curing and after subjecting the composites to accelerated aging.

The typical bending curves for the cured composites and the cured and aged composites are presented in Figure 12. The average values and standard deviation of limit of proportionality (LOP), modulus of rupture (MOR), modulus of elasticity (MOE), and toughness obtained from the bending curves are presented in Figure 13. 

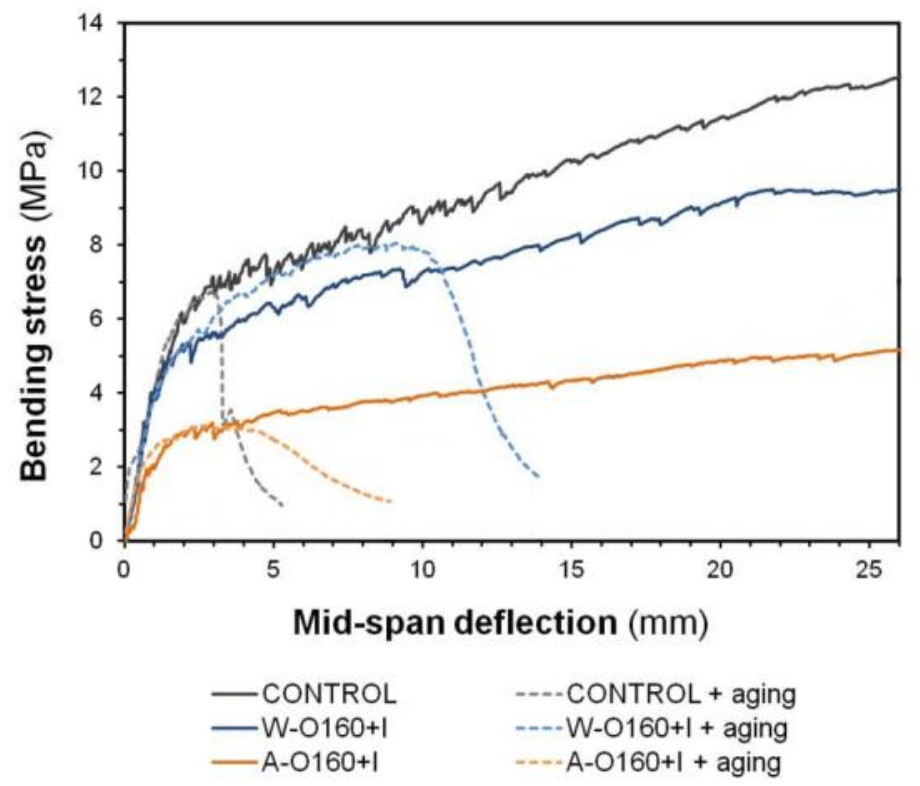

Figure 12. Typical bending curves of the cured and the cured and aged composites prepared with the uncreated nonwoven (control) and the ones prepared with the nonwovens treated under different conditions.
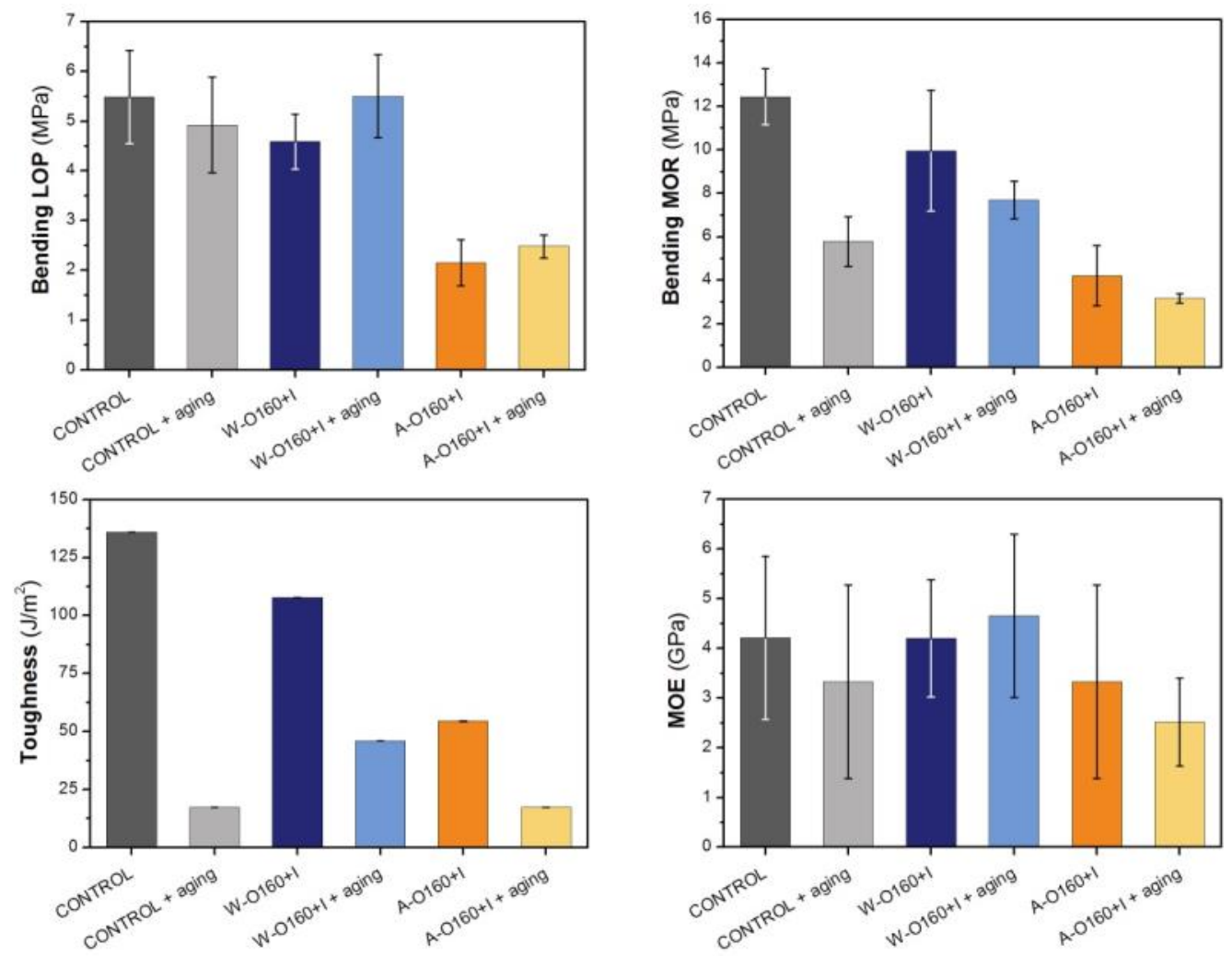

Figure 13. Average values of LOP, MOR, toughness, and MOE of the cured and the cured and aged composites prepared with the uncreated nonwoven (control) and the ones prepared with the nonwovens treated under different conditions. 
As shown, with regard to the unaged composites, there is a reduction of the mechanical performance for those prepared with the treated nonwovens. For the W-O160+I treatment, there is a decrease of around $20 \%$ in the MOR values, while for the A-O160+I treatment the decrease is around $66 \%$. Nonetheless, it can be also observed that this worsening of the performance of the composites occurs at the level of the matrix; that is to say, there is a reduction of the LOP. After the first cracking of the matrix, the behavior is similar for all the samples; the nonwoven allows a deformation of more than $25 \mathrm{~mm}$ of mid-span deflection.

This result can be explained by the difference in the chemical surface's composition of the the nonwovens after the treatments, which led to different interaction between the fibers and the matrix.

For the composites cured and subjected to accelerated aging, a reduction of the reinforcement effect provided by the nonwovens can be observed for high deformations; that is to say, for deformations greater than $3 \mathrm{~mm}$ of mid-span deflection (Figure 12). For the three composites studied, the initial behavior is similar and the curves maintain the characteristics of the unaged composites. For the control sample there is a sudden drop in strength at a mid-span deflection of about $3 \mathrm{~mm}$, indicating fiber breakage, as observed in the fracture section. For the other samples, the curve maintained a strain hardening behavior until around $4.5 \mathrm{~mm}$ of mid-span deflection for the composites prepared with the nonwoven treated in the autoclave and up to around $10 \mathrm{~mm}$ for the ones with the ovendried nonwoven. In both cases the curves were very similar to those for the unaged composites. These results can also be seen in Figure 13. As shown, the LOP values of the aged samples are similar to or even higher than those of the unaged ones. This is because this value basically depends on the strength of the matrix, which can be more hydrated after aging. Similar results were found for MOE values, where the strength of the matrix is the main component that affects the behavior of the composite.

With respect to the MOR values, the high ductility of this material causes it to break at very high deformations (even higher than the limit established by RILEM for this kind of test) (Figure 14). This leads to a decrease in the MOR values of around $20 \%$ for the W-O160+I and A-160+I aged composites, although the curves remain parallel to those of the unaged composites until failure. However, it must be taken into account that a plate of $30 \times 30 \mathrm{~cm}$ will have hardly any deformation higher than $10 \mathrm{~mm}$, so the $\mathrm{W}-\mathrm{O} 160+\mathrm{I}$ composite will have adequate performance after aging. 


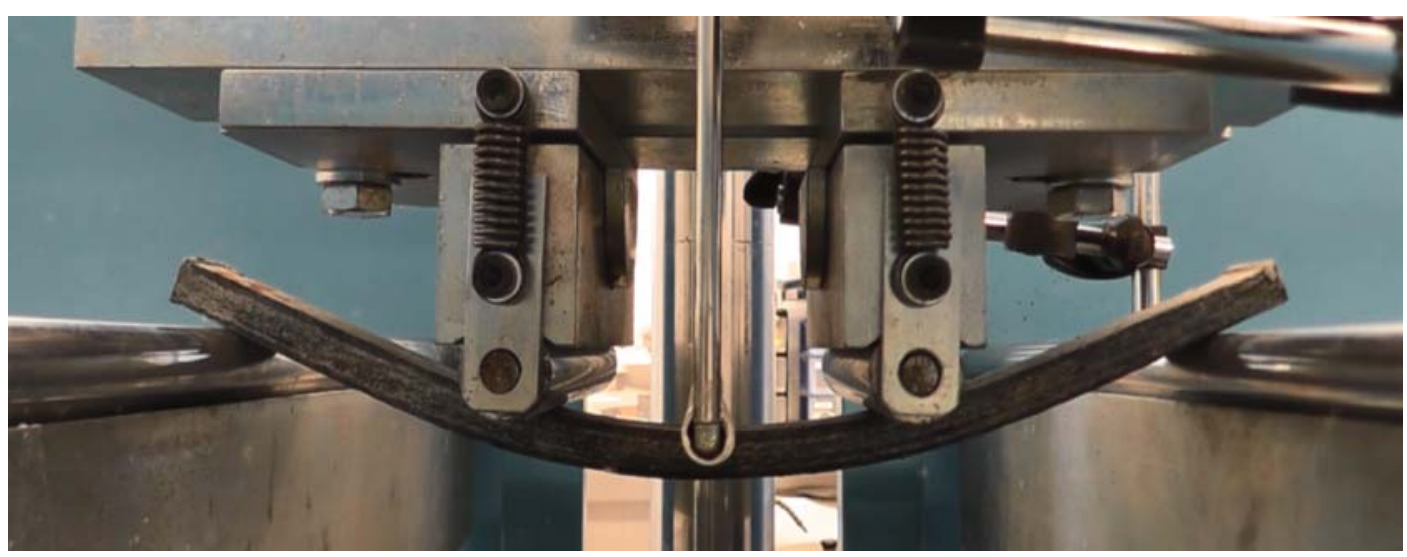

Figure 14. Example of the end of the test for one unaged composite

With respect to the toughness, the aged composites show values more than $50 \%$ lower than the unaged ones. This reduction in the fracture energy is a consequence of the fiber debonding and mineralization. Nonetheless, if the limit were established at $10 \mathrm{~mm}$ of mid-span deflection, the toughness of the W-O160+I aged composite would be similar to or even higher than that of the unaged one.

This improvement in the durability mainly for the W-O160+I composite may be related to an improvement of the stability of the fiber-matrix interface due to the higher dimensional stability of the fibers with respect to moisture changes. So, the hybrid treatments proposed in this paper are effective in preventing the loss of fiber-matrix bonding induced by dimensional changes in these fibers. This result is in good agreement with the previous results obtained by our research group with other cellulosic fibers [42].

\subsection{Considerations for applications of the materials developed for the ventilated façade's plates}

From the point of view of technological application, the use of this material for façade plates can provide many advantages. Concerning the mechanical properties, their performance is sufficiently good to fulfill the requirements of such applications with a thickness of around $10 \mathrm{~mm}$ and very low weight (the densities of the plates are around $\left.1.6 \mathrm{~g} / \mathrm{cm}^{3}\right)$. This, combined with their high ductility, allows low-complexity structures to be developed. Moreover, these materials present dimensional variations around $0.14 \%$, $0.15 \%$ and $-0.8 \%$ for the length, width and thickness respectively, meeting more than the tolerance requirements of the UNE-EN12467 Standard. 
On the other hand, their manufacture using a continuous process where the nonwoven is embedded in the matrix followed by molding allows coatings with different colors, textures, or catalytic functions, if necessary. An example of plates produced with Ordinary Portland cement (middle) and with white Portland cement with or without pigments (right and left plates respectively) is pictured in Figure 15.

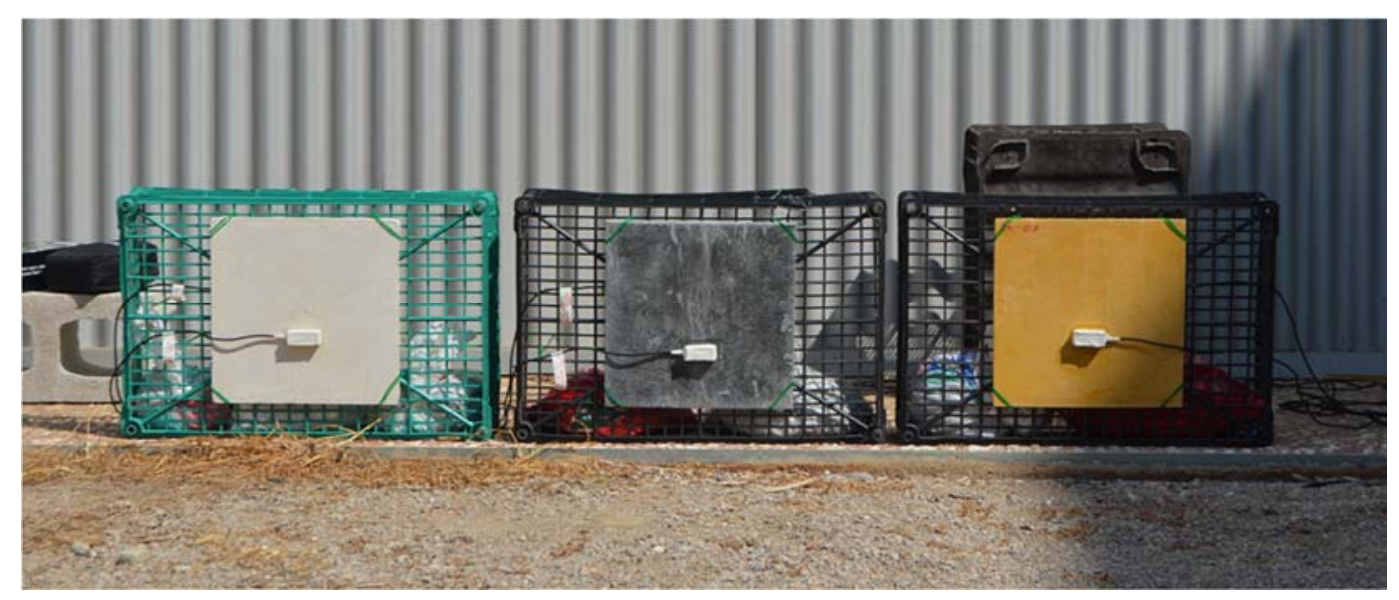

Figure 15. Images of various developed façade plates

Finally, this material has a considerably lower $\mathrm{CO}_{2}$ footprint than other materials typically used for this application, as can be seen in Figure 15. The calculation has been done considering only one façade plate and the $\mathrm{CO}_{2}$ necessary for the production of the raw materials and the manufacture of the plates. The database used was CES EDUPAC 2012 (Granta Material Intelligence, spin-off company from Cambridge University) 


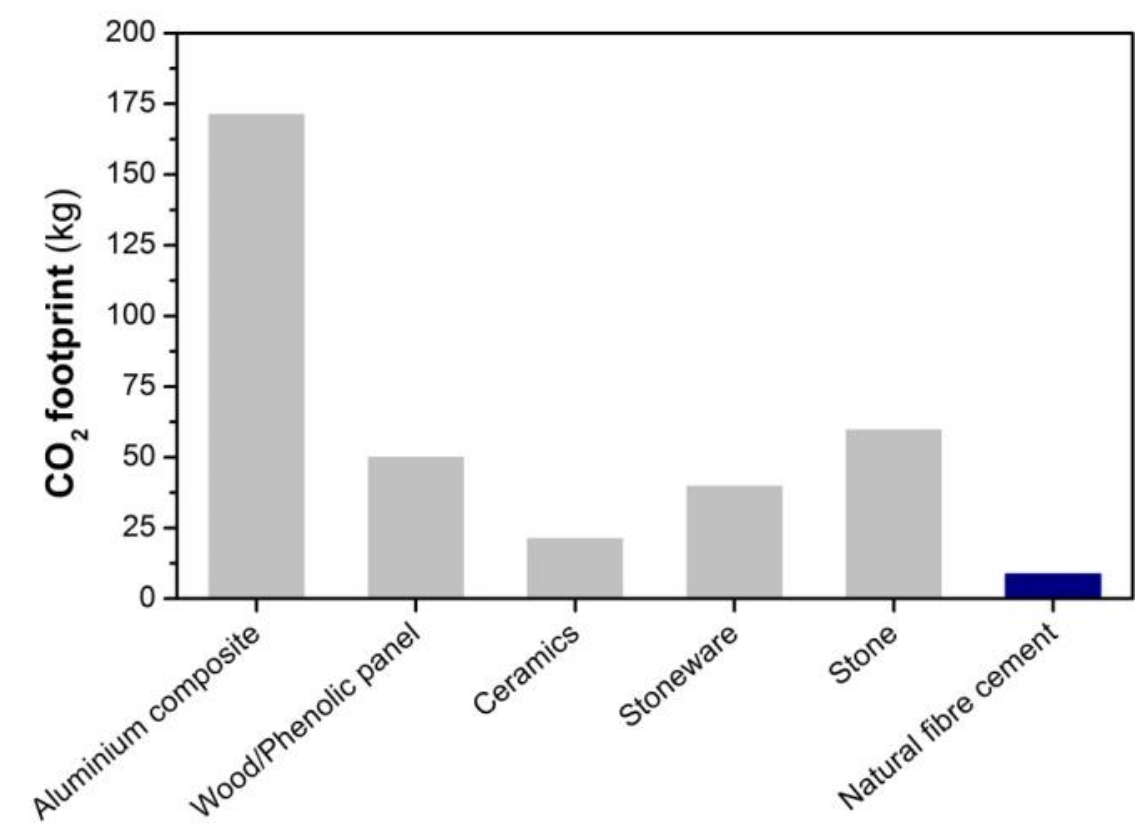

Figure 16. Estimated values of $\mathrm{CO}_{2}$ footprint for various materials typically used for ventilated façade plates compared with the material developed in this research

\section{Conclusions}

- The pozzolanic additions allow a reduction in the $\mathrm{Ca}(\mathrm{OH})_{2}$ content of the matrix, mainly for the samples with higher pozzolan contents. For these samples, the compressive strength is mainly developed during the first 28 days of curing while the flexural strength is developed between 28 and 56 days.

- The treatments of wetting and drying in different conditions make it possible to improve the tensile strength of the nonwovens and to reduce the water absorption. The highest values of breaking force combined with the lowest values of water absorption were found for the W-O160+I and A-O160+I samples. Nevertheless the last treatment seems to modify the chemical surface of the fibers, leading to composites with poorer properties.

- The best treatment was found to be W-O160+I, since it yielded composites with significantly less loss of toughness after aging. 
- The composites presented in this research will allow the development of new materials for ventilated façade plates with higher performance and sustainability than those typically used for these applications.

\section{Acknowledgments}

The authors gratefully acknowledge MINECO (Government of Spain) for financial support of this work (project BIA2014-59399-R and scholarship FPU12/05869).

\section{References}

[1] N. Stern, The Economics of Climate Change: The Stern Review, Cambridge University Press, Cambridge, 2007.

[2] European Comission, Energy efficiency: delivering the 20\% target, (2009).

[3] U.N.E. Programme, Buildings and Climate Change. Summary for DecisionMakers, 2009.

[4] J. Giesekam, J. Barrett, P. Taylor, A. Owen, The greenhouse gas emissions and mitigation options for materials used in UK construction, Energy Build. 78 (2014) 202-214. doi:10.1016/j.enbuild.2014.04.035.

[5] D.D. Tingley, A. Hathway, B. Davison, An environmental impact comparison of external wall insulation types, Build. Environ. 85 (2015) 182-189. doi:10.1016/j.buildenv.2014.11.021.

[6] H. Savastano, P.G. Warden, R.S.P. Coutts, Brazilian waste fibres as reinforcement for cement-based composites, Cem. Concr. Compos. 22 (2000) 379-384. doi:10.1016/S0958-9465(00)00034-2.

[7] H. Savastano, P.. Warden, R.S.. Coutts, Potential of alternative fibre cements as building materials for developing areas, Cem. Concr. Compos. 25 (2003) 585592. doi:10.1016/S0958-9465(02)00071-9.

[8] R.D. Tolêdo-Filho, K. Ghavami, G.L. England, K. Scrivener, Development of vegetable fibre-mortar composites of improved durability, Cem. Concr. Compos. 25 (2003) 185-196. doi:10.1016/S0958-9465(02)00018-5.

[9] M. Ardanuy, J. Claramunt, R.D. Toledo Filho, Cellulosic fiber reinforced cement-based composites: A review of recent research, Constr. Build. Mater. 79 (2015) 115-128. doi:10.1016/j.conbuildmat.2015.01.035.

[10] G.H.D. Tonoli, H. Savastano, E. Fuente, C. Negro, a. Blanco, F. a. Rocco Lahr, Eucalyptus pulp fibres as alternative reinforcement to engineered cement-based composites, Ind. Crops Prod. 31 (2010) 225-232.

doi:10.1016/j.indcrop.2009.10.009.

[11] H. Savastano, a. Turner, C. Mercer, W.O. Soboyejo, Mechanical behavior of cement-based materials reinforced with sisal fibers, J. Mater. Sci. 41 (2006) 6938-6948. doi:10.1007/s10853-006-0218-1. 
[12] H. Savastano, P.G. Warden, R.S.P. Coutts, Mechanically pulped sisal as reinforcement in cementitious matrices, 25 (2003) 311-319.

[13] B.J. Mohr, H. Nanko, K.E. Kurtis, Durability of thermomechanical pulp fibercement composites to wet/dry cycling, Cem. Concr. Res. 35 (2005) 1646-1649. doi:10.1016/j.cemconres.2005.04.005.

[14] P. Soroushian, M. Elzafraney, A. Nossoni, H. Chowdhury, Evaluation of normalweight and light-weight fillers in extruded cellulose fiber cement products, Cem. Concr. Compos. 28 (2006) 69-76. doi:10.1016/j.cemconcomp.2004.01.007.

[15] B.J. Mohr, H. Nanko, K.E. Kurtis, Aligned kraft pulp fiber sheets for reinforcing mortar, Cem. Concr. Compos. 28 (2006) 161-172. doi:10.1016/j.cemconcomp.2005.08.004.

[16] J. Claramunt, M. Ardanuy, F. Parés, H. Ventura, Mechanical performance of cement mortar composites reinforced with cellulose fibres., in: M. Meo (Ed.), 9th Int. Conf. Compos. Sci. Technol., DESTech Publications, 2013: pp. 477-484.

[17] V. Agopyan, H. Savastano, V.M. John, M. a. Cincotto, Developments on vegetable fibre-cement based materials in São Paulo, Brazil: an overview, Cem. Concr. Compos. 27 (2005) 527-536. doi:10.1016/j.cemconcomp.2004.09.004.

[18] R.D. Toledo Filho, F.D.A. Silva, E.M.R. Fairbairn, J.D.A.M. Filho, Durability of compression molded sisal fiber reinforced mortar laminates, Constr. Build. Mater. 23 (2009) 2409-2420. doi:10.1016/j.conbuildmat.2008.10.012.

[19] F. de Andrade Silva, B. Mobasher, R.D.T. Filho, Fatigue behavior of sisal fiber reinforced cement composites, Mater. Sci. Eng. A. 527 (2010) 5507-5513. doi:10.1016/j.msea.2010.05.007.

[20] F.D.A. Silva, B. Mobasher, R.D.T. Filho, Cracking mechanisms in durable sisal fiber reinforced cement composites, Cem. Concr. Compos. 31 (2009) 721-730. doi:10.1016/j.cemconcomp.2009.07.004.

[21] F.D.A. Silva, D. Zhu, B. Mobasher, C. Soranakom, R.D. Toledo Filho, High speed tensile behavior of sisal fiber cement composites, Mater. Sci. Eng. A. 527 (2010) 544-552. doi:10.1016/j.msea.2009.08.013.

[22] J. Claramunt, L.J. Fernandez-Carrasco, M. Ardanuy, Mechanical behavior of flax nonwoven cement composites, in: E. Schlangen, M.G. Sierra-Beltran, M. Lukovic, G. Ye (Eds.), SHCC3- Strain Hardening Cem. Compos. B. Proc., RILEM, 2014.

[23] J. Claramunt, H. Ventura, F. Parés, M. Ardanuy, Natural fibre nonwovens as reinforcement for cement mortar composites, in: R. Fangueiro (Ed.), B. Abstr. 1st Int. Conf. Nat. Fibers Sustain. Mater. Adv. Appl., Universidade do Minho, 2013: pp. 191-192.

[24] J. Claramunt, M. Ardanuy, L. Fernandez-Carrasco, H. Ventura, Producto de material compuesto de aglomerante inorgánico y fibras vegetales, y método para su fabricación, N. de solicitud: P201430772, 2014.

[25] B.J. Mohr, H. Nanko, K.E. Kurtis, Durability of kraft pulp fiber-cement composites to wet/dry cycling, Cem. Concr. Compos. 27 (2005) 435-448. doi:10.1016/j.cemconcomp.2004.07.006. 
[26] R.D. Tolêdo Filho, K. Scrivener, G.L. England, K. Ghavami, Durability of alkalisensitive sisal and coconut fibres in cement mortar composites, Cem. Concr. Compos. 22 (2000) 127-143. doi:10.1016/S0958-9465(99)00039-6.

[27] M. Ardanuy, J. Claramunt, J.A. García-Hortal, M. Barra, Fiber-matrix interactions in cement mortar composites reinforced with cellulosic fibers, Cellulose. 18 (2011) 281-289. doi:10.1007/s10570-011-9493-3.

[28] P.W.B. N.Y. Mostafa, S. A. S. El-Hemaly, E.I. Al-Wakeel, S. A. El-Korashy, Characterization and evaluation of the pozzolanic activity of Egyptian industrial by-products: I: Silica fume and dealuminated kaolin, Cem. Concr. Res. 31 (2001) 467-474.

[29] S.P.P. R.L. Sharma, Influence of mineral additives on the hydration characteristics of ordinary Portland cement, Cem. Concr. Res. 29 (1999) 15251529 .

[30] H. Savastano, S.F. Santos, M. Radonjic, W.O. Soboyejo, Fracture and fatigue of natural fiber-reinforced cementitious composites, Cem. Concr. Compos. 31 (2009) 232-243. doi:10.1016/j.cemconcomp.2009.02.006.

[31] G.A. Rao, Influence of silica fume on long-term strength of mortars containing different aggregate fractions, Cem. Concr. Res. 31 (2001) 7-12.

[32] A.M. Rashad, Alkali-activated metakaolin: A short guide for civil Engineer-An overview, Constr. Build. Mater. 41 (2013) 751-765.

[33] J.B. B. Sabir, S. Wild, Metakaolin and calcined clays as pozzolans for concrete: A review, Cem. Concr. Compos. 23 (2001) 441-454.

[34] H.A.R. H.S. Wong, Efficiency of calcined kaolin and silica fume as cement replacement material for strength performance, Cem. Concr. Res. 35 (2005) 696702.

[35] R.K. J. Zelić, D. Rušić, D. Veža, Role of silica fume in the kinetics and mechanisms during the early stage of cement hydration, Cem. Concr. Res. 30 (2000) 1655-1662.

[36] M. Ardanuy, J. Claramunt, R.D. Toledo Filho, Cellulosic fiber reinforced cement-based composites: A review of recent research, Constr. Build. Mater. 79 (2015) 115-128. doi:10.1016/j.conbuildmat.2015.01.035.

[37] M. Cyr, M. Trinh, B. Husson, G. Casaux-ginestet, Cement and Concrete Research Effect of cement type on metakaolin ef fi ciency, 64 (2014) 63-72. doi:10.1016/j.cemconres.2014.06.007.

[38] D.H. Page, P.A. Tydeman, Transverse swelling and shrinkage of softwood tracheid, Nature. 199 (1963) 471-472.

[39] U. Weise, H. Paulapuro, Effect of drying and rewetting cycles on fibre swelling, J. Pulp Pap. Sci. 25 (1999) 163-166.

[40] J. Claramunt, M. Ardanuy, J.A. García-Hortal, Effect of drying and rewetting cycles on the structure and physicochemical characteristics of softwood fibres for reinforcement of cementitious composites, Carbohydr. Polym. 79 (2010) 200205.

[41] C. Ackermann, L. Göttsching, H. Pakarinen, Recycled fiber and deinking, in: L. 
Göttsching, H. Pakarinen (Eds.), Papermak. Sci. Technol. Recycl. Fiber Deinking, Finnish Paper Engineers' Association, Finland, 2000: pp. 359-438.

[42] J. Claramunt, M. Ardanuy, J.A. García-Hortal, R.D.T. Filho, The hornification of vegetable fibers to improve the durability of cement mortar composites, Cem. Concr. Compos. 33 (2011) 586-595. doi:10.1016/j.cemconcomp.2011.03.003.

[43] J.E. Mejia Ballesteros, S.F. Santos, G. Mármol, H. Savastano, J. Fiorelli, Evaluation of cellulosic pulps treated by hornification as reinforcement of cementitious composites, Constr. Build. Mater. 100 (2015) 83-90. doi:10.1016/j.conbuildmat.2015.09.044.

[44] S.R. Ferreira, P.R.. Lima, F.A. Silva, R.D. Toledo Filho, Effect of Sisal Fiber Hornification on the Fiber-Matrix Bonding Characteristics and Bending Behavior of Cement Based Composites, Key Eng. Mater. 600 (2014) 421-432. doi:10.4028/www.scientific.net/KEM.600.421.

[45] R.S.P. Coutts, Y. Ni, Autoclaved bamboo pulp fibre reinforced cement, Cem. Concr. Compos. 17 (1995) 99-106. doi:10.1016/0958-9465(94)00002-G.

[46] M. Cyr, M. Trinh, B. Husson, G. Casaux-Ginestet, Effect of cement type on metakaolin efficiency, Cem. Concr. Res. 64 (2014) 63-72. doi:10.1016/j.cemconres.2014.06.007.

[47] B.J. Mohr, J.J. Biernacki, K.E. Kurtis, Supplementary cementitious materials for mitigating degradation of kraft pulp fiber-cement composites, Cem. Concr. Res. 37 (2007) 1531-1543. doi:10.1016/j.cemconres.2007.08.001.

[48] L. Fernández-Carrasco, J. Claramunt, M. Ardanuy, Autoclaved cellulose fibre reinforced cement: Effects of silica fume, Constr. Build. Mater. 66 (2014) 138145. doi:10.1016/j.conbuildmat.2014.05.050.

[49] A. Stamboulis, C.A. Baillie, T. Peijs, Effects of environmental conditions on mechanical and physical properties of flax fibers, Compos. Part A Appl. Sci. Manuf. 32 (2001) 1105-1115. doi:10.1016/S1359-835X(01)00032-X. 